\title{
Effects of Nutritional Counseling on the Anthropometric and Biochemical Nutritional Data of Obese Workers: a Randomized Blind Study
}

\author{
Roberta SL Cassani $^{1,2}$, Selma FC Cunha ${ }^{2}$, Andre LG Freitas ${ }^{1}$, Carla B Nonino ${ }^{2}$, Julio S Marchini ${ }^{2, *}$ \\ ${ }^{1}$ Institute of Nutrition, ITU, Brazil \\ ${ }^{2}$ Medicine Department \& School of Medicine of Ribeirão Preto, São Paulo University, Ribeirão Preto, 14049-900, Brazil \\ *Corresponding Aurhor: jsmarchi@fmrp.usp.br
}

Copyright (C) 2013 Horizon Research Publishing All rights reserved

\begin{abstract}
The intake of processed foods of high calorie density is associated with weight gain and changes in lipid and cardiovascular metabolism. However, the modification of eating habits is possible due to, among other factors, information provided to patients about the foods/nutrients ingested. The present investigation observed the impact of nutritional counseling on anthropometric and on biochemical indicators in a blind controlled study. Therefore, a single investigator counseled obese workers divided into three groups over a period of 42 days. A control group (CG) received no counseling. GLi50 received $60 \mathrm{~g} / \mathrm{d}$ linseed and $50 \%$ of the energy supply as carbohydrates; GRi50 received $60 \mathrm{~g} / \mathrm{d}$ raw ground rice and $50 \%$ of the energy supply as carbohydrates, and GLi32 received $60 \mathrm{~g} / \mathrm{d}$ linseed and 32\% of the energy supply as carbohydrates. A total of 118 volunteers started the protocol and 52 completed it. The most consumed foods were rice, beans, bread, manioc flour, soy oil, red meat, and eggs. CG did not show any modifications. The remaining groups, regardless of diet composition, showed a reduction of anthropometric measurements, besides reduced glycemia, cholesterolemia, triglycerides and insulinemia, as well as reduced peripheral resistance to the action of insulin. More important than supplementation or the proportion of carbohydrates ingested, nutritional counseling was the common factor for adequacy of energy intake, weight loss and improved biochemical indicators. Nutrition counseling can be a viable and economically strategy for helping patients with life style diseases.
\end{abstract}

Keywords Obesity, Nutritional Counseling, Insulin, Linseed, Cholesterol

\section{Introduction}

The intake of processed foods of high calorie density is associated with weight gain and changes in lipid and cardiovascular metabolism [1-4]. In parallel, the modification of eating habits is influenced, among other factors, by information/counseling provided to patients about the foods/nutrients ingested. This process is based on constant and active counseling, with repetition and reinforcement of modifiable food/nutrient characteristics. Thus, counseling depends on patient's disease, on preventive and/or curative aspects, on the cognitive level of the patient and on the availability and technical skill of the counselor.

However, nutrition counseling is not always a measurable and comparable process. Thus, a given type of counseling is validated by means of studies in which the subjects do not know which procedures or medications they are being submitted to (blind study). In addition, control group subjects do not receive any counseling/information [5]. The evaluation of food intake and later nutrition counseling are important as a contribution to treatment and for the modification of eating habits, preventing the recurrence of nutritional disorders [6].

The eating habits of individuals with cardiovascular diseases (CVD) often contribute to the high morbidity of this group of patients [7]. One characteristic of the nutrient intake of CVD patients is the high consumption of fast-absorbed carbohydrates $(\mathrm{CH})$, total fats, saturated and trans fatty acids, which contributes to disorders such as hypercholesterolemia, aggravation of systemic arterial hypertension, and higher peripheral resistance to the action of insulin [8].

The objective of the present study was to associate dietary factors with anthropometric and biochemical markers in overweight and obese volunteers living in a healthy environment, and to observe the impact of nutritional counseling on these markers. The participants in the experiment did not know what they were ingesting as a supplement in their daily diet (blind study). Our hypothesis was that nutritional counseling is useful by reducing anthropometry and biochemical data, including insulin resistance, by leading to adequate energy intake.

\section{Materials and Methods}




\subsection{Subjects and experimental protocol}

The volunteers participating in the study were workers from the food industry (Beer and Soft Drinks Industry Primo Schincariol SA, Itu, Brazil). Only workers clinically classified as obese participated. The subjects were later divided into 4 groups, 3 experimental ones and a control one. The volunteers in the experimental groups did not know to which group they belonged (blind study). Cultural and economic indicators were similar for all participants, who were assigned to each group at random by drawing lots. The experimental groups were then submitted to nutrition counseling as described below.

A single investigator always provided counseling over a defined period of time (42 days) and the volunteers were evaluated at the beginning and at the end of the experimental period. The Ethics Committee of the University Hospital of Ribeirão Preto, University of São Paulo, SP, approved the study, and all volunteers signed a consent form.

The control group (GCo) consisted of workers who did not receive any nutrition counseling or food supplement. The first experimental group (GLi50) consisted of subjects who received a linseed supplement $(60 \mathrm{~g} / \mathrm{d})$ and $50 \%$ of the energy supply as $\mathrm{CH}$. The second experimental group (GRi50) consisted of those who received a supplement of raw ground rice $(60 \mathrm{~g} / \mathrm{d})$ and $50 \%$ of the energy supply as $\mathrm{CH}$. Finally, the third experimental group (GLi32) received a linseed supplement $(60 \mathrm{~g} / \mathrm{d})$ and $32 \%$ of the energy supply as $\mathrm{CH}$. The total energy supply and the supply of all other nutrients were similar for GLi50, GRi50 and GLi32.

In the present study, brown linseed and rice were used to supplement the diets under nutritional intervention. Both linseed and rice were part of the same food lots, ground and stored in the Nutrition Service of the industry. The supplements were delivered at snack time and at lunch, respectively, administered in skim milk and in bean broth. The volunteers of the GLi50, GRi50 and GLi32 groups did not know what type of supplementation they were receiving, a fact that characterized the present study as a blind one.

The Medical Team of the workplace of the participants made the medical diagnosis, with no interference by the research team. Volunteers with a medical diagnosis of hepatic, renal or digestive diseases were excluded from the study. Also excluded were workers who were taking lipid-lowering medications or who had undergone prior treatment for weight loss, taking medications, and workers who were on vacation or who were supposed to take previously scheduled work trips after the beginning of the protocol. On the basis of anthropometry, the participants were classified as overweight when their body mass index (BMI) ranged from 25 to $30 \mathrm{~kg} / \mathrm{m}^{2}$ and obese when BMI was 31 to $45 \mathrm{~kg} / \mathrm{m}^{2}$. All subjects were evaluated regarding habitual food intake, anthropometry and biochemical indicators related to changes in lipid and cardiovascular metabolism determined after an 8 hour fast.

\subsection{Anthropometry}

Anthropometric evaluation was based on the following measurements: weight $(\mathrm{kg})$, height $(\mathrm{cm}), \mathrm{BMI}\left(\mathrm{kg} / \mathrm{m}^{2}\right)$, and abdominal circumference $(\mathrm{AC}, \mathrm{cm})$ measured at the midpoint between the iliac crest and the last rib. The hip circumference $(\mathrm{HC}, \mathrm{cm})$ defined as the largest circumference between the waist and the knees was measured at the height of the trochanter points (right and left) and passing through the gluteal prominence. The abdomen/hip ratio (AHR) was calculated as the quotient of these values [9]. The subscapular fold (mm), directly related to cardiovascular risk [7], was measured immediately below the inferior angle of the right scapula using a Lange caliper (Beta Technology Incorporated, USA) with a $0-60 \mathrm{~mm}$ scale, at a constant pressure of $10 \mathrm{~g} / \mathrm{mm}^{2}$, positioned obliquely to the longitudinal axis, with the subject standing up and curving his arm backwards [9-10].

\subsection{Biochemical analyses}

The following biochemical indicators were used: glucose $(\mathrm{mg} / \mathrm{dL})$, total cholesterol $(\mathrm{mg} / \mathrm{dL})$, low density lipoprotein (LDL-c, mg/dL), high density lipoprotein (HDL-c, mg/dL), triglycerides (TG, $\mathrm{mg} / \mathrm{dL}$ ), uric acid $(\mathrm{mg} / \mathrm{dL}$ ), insulin $(\mu \mathrm{IU} / \mathrm{mL})$, HOMA B, and HOMA IR. Glycemia was determined by an enzymatic method using a HITACHI 912®ROCHE instrument (Japan) and reference values of 70 to $99 \mathrm{mg} / \mathrm{dL}$ [11]. Total cholesterol and HDL-c were determined by an enzymatic method using the same HITACHI 912®- ROCHE instrument. The reference values used for total cholesterol in subjects older than 19 years were less than $200 \mathrm{mg} / \mathrm{dL}$, desirable range; 200 to $239 \mathrm{mg} / \mathrm{dL}$, borderline range; and above $239 \mathrm{mg} / \mathrm{dL}$, elevated [12]. The reference values for HDL-c were less than $40 \mathrm{mg} / \mathrm{Dl}$, increased risk; higher than $40 \mathrm{mg} / \mathrm{dL}$, desirable; higher than $60 \mathrm{mg} / \mathrm{dL}$, excellent [12]. LDL-c was determined by the Friedewald formula. Volunteers who had $\mathrm{TG} \geq 400 \mathrm{mg} / \mathrm{dL}$ had their LDL-cholesterol determined by an enzymatic method with the HITACHI 912® ROCHE instrument. The reference values used for subjects older than 19 years were less than $100 \mathrm{mg} / \mathrm{dL}$, excellent; 100 to $129 \mathrm{mg} / \mathrm{dL}$, sub-optimal; 130 to $159 \mathrm{mg} / \mathrm{dL}$, borderline; 160 to 189 $\mathrm{mg} / \mathrm{dL}$, elevated; higher than $189 \mathrm{mg} / \mathrm{dL}$, very elevated [12]. Triglycerides were determined by an enzymatic method with the HITACHI 912®- ROCHE instrument. The reference values used for subjects older than 19 years were less than $150 \mathrm{mg} / \mathrm{dL}$, normal; 150 to $199 \mathrm{mg} / \mathrm{dL}$, borderline; 200 to $499 \mathrm{mg} / \mathrm{dL}$, elevated; above $499 \mathrm{mg} / \mathrm{dL}$, very elevated [12]. Uric acid concentrations were determined by an enzymatic method with the HITACHI 912 $®$ - ROCHE instrument. The reference values used for males were 3.4 to $7.0 \mathrm{mg} / \mathrm{dL}$. Insulinemia was determined by chemoluminescence using the IMMULITE 1000 SYSTEMS $®$ - SIEMENS MEDICAL SOLUTIONS DIAGNOSTICS (SIEMENS) (Los Angeles, USA). The reference values ranged from 2.5 to $28.4 \mu \mathrm{IU} / \mathrm{mL}$. The HOMA index is based on fasting plasma concentrations of glucose and basal insulin in order to predict insulin resistance (HOMA-IR), and the 
functional capacity of pancreatic beta cells (HOMA B) as percentages of a normal reference population. HOMA indices were obtained using specific formulas [13].

\subsection{Dietary counseling}

Next, all subjects, except those in the GCo group, were individually submitted to dietary counseling with detailed explanations about total energy intake, differences between the types of fat ingested, fast absorbed carbohydrates, and total proteins. It was explained individually to each participant that the energy supply should be appropriate for the physical activities performed and that it should range from 1500 to $2000 \mathrm{kcal}$, with $60 \mathrm{~g}$ protein per day, corresponding to approximately $20 \%$ of the energy supply. Concerning dietary adherence, the participants were monitored weekly and the total experiment lasted 42 days. At the end of the experiment, each participant was evaluated individually, as done at the beginning of the study. Analysis of the composition of the habitual diet, based on the Semi-Quantitative Food Frequency Questionnaire, assesses the food intake for the previous 6 months. The dietetic data were processed with specific software (NutWin $1.5{ }^{\circledR}$ Professional Software; Federal University of São Paulo, São Paulo, Brazil).

The dietary counseling was based on the following assumptions [14]: a) limited energy intake, especially from $\mathrm{CH} ; \mathrm{b})$ replacement of saturated fats with unsaturated fats; c) exclusion of trans fats from the diet; increased consumption of fruits and vegetables (at least $400 \mathrm{~g} / \mathrm{d}$ ); d) consumption of oleaginous foods and foods containing a large amount of fibers, and limitation of the consumption of free sugars and salt $(\mathrm{NaCl})$.

During the counseling interviews, each volunteer was stimulated to continue to follow the guidance provided throughout the study and to maintain his daily life activities at a constant level, with no suggestion of insertion or increase of physical activity.

\subsection{Statistical analysis}

Data were analyzed by within-group paired comparison (final and initial moments) and by between- group unpaired comparison. Parametric and nonparametric methods were used as necessary. Data are reported as mean and standard deviation, with the level of significance set at $5 \%$.

\section{Results}

Data collection occurred as planned, with no intercurrences. A total of 118 volunteers were initially evaluated. Of these, 66 did not agree to participate or were excluded according to the criteria described earlier. Thus, 52 volunteers concluded the study. Table 1 presents the anthropometric characteristics of the volunteers and control subjects evaluated. Table 2 presents the respective biochemical results and Table 3 summarizes the nutrient intake reported at the beginning (baseline) and at the end of the study. The food intake reported at the beginning of the study reflects the usual intake of each participant and the final values reflect the result of nutritional counseling. The volunteers had no restriction regarding their food supply at any time during the study. The final modification was the result of the 42 days of nutrition counseling to which the volunteers were submitted. The food frequency questionnaire revealed that the foods most consumed weekly by the workers were white rice, beans, bread, manioc flour, soy oil, red meat and eggs, with a less frequent intake of fruits and vegetables.

\section{Discussion}

The main results of the present study show that the groups that received dietary counseling had a similar weight loss regardless of the composition of the supplement or of the $\mathrm{CH}$ content. The changes in the biochemical determinations showed the same behavior. On the other hand, these results were not observed in the GCo. On this basis, the role of individual counseling within this double-blind study was sufficient to elicit an improvement regarding weight loss, glycemia, uric acid, insulinemia, and HOMA index. These results are surprising since the dietary pattern, regardless of the supplement or the total amount of energy ingested, induced metabolic changes related to a desirable health status. It was observed that counseling about a prudent dietary pattern was well accepted and maintained as long as the nutritional guidelines were frequently provided.

The results of energy intake agree with those reported by others [15]. In the present study, regardless of diet composition, energy reduction was associated with, or was a determinant factor of, weight loss and of the reduction of anthropometric measurements related to visceral fat [15]. Meals with a high-energy content, rich in processed foods and rapidly digested and quickly absorbed foods are responsible for significant increases in blood glucose and triglyceride concentrations [16-17].

The present study showed that dietary information provided in a sequential manner, with adequate nutrient intake, especially the reduction of fast absorbed $\mathrm{CH}$ and saturated and trans fats, reduced the plasma concentrations of glucose and fatty acids. Thus, a lower production of free radicals appears to occur, associated with lower LDL-c oxidation and lower vasoconstriction [18]. On the other hand, the intake of vegetables, fruits, oleaginous foods, seeds and grains increases the postprandial glucose and triglycerides but to lower levels than the intake of processed foods, possibly because these meals have a lower glycemic load and a higher content of fibers and water [19]. It also should be pointed out that linseed intake alone has a positive effect preventing the risk of cardiovascular disease [20-21]. 
Table 1. Anthropometric characteristics of the participants in the present study.

\begin{tabular}{|c|c|c|c|c|c|}
\hline & \multicolumn{3}{|c|}{ Experimental groups } & \multirow[b]{2}{*}{$\mathrm{GRi}_{50}(\mathrm{n}=13)$} & \multirow[b]{2}{*}{$\mathrm{GLi}_{32}(\mathrm{n}=14)$} \\
\hline & Time & $\operatorname{GCo}(n=11)$ & $\mathrm{GLi}_{50}(\mathrm{n}=14)$ & & \\
\hline Weight kg & Initial & $78 \pm 12$ & $98 \pm 20 * \#$ & $95 \pm 11 *$ & $96 \pm 14 * \#$ \\
\hline BMI kg/m² & $\begin{array}{l}\text { Final } \\
\text { Initial }\end{array}$ & $\begin{array}{l}79 \pm 12 \\
27 \pm 4\end{array}$ & $\begin{array}{l}92 \pm 20 \\
34 \pm 6^{*}\end{array}$ & $\begin{array}{l}88 \pm 10 \\
32 \pm 3 * \#\end{array}$ & $\begin{array}{l}90 \pm 14 \\
32 \pm 3 * \#\end{array}$ \\
\hline $\mathrm{AC} \mathrm{cm}$ & $\begin{array}{l}\text { Final } \\
\text { Initial }\end{array}$ & $\begin{array}{l}28 \pm 4 \\
96 \pm 10\end{array}$ & $\begin{array}{l}32 \pm 7 \\
113 \pm 17 * \#\end{array}$ & $\begin{array}{l}30 \pm 3 \\
107 \pm 8^{*}\end{array}$ & $\begin{array}{l}30 \pm 4 \\
108 \pm 8^{*}\end{array}$ \\
\hline $\mathrm{HC} \mathrm{cm}$ & $\begin{array}{l}\text { Final } \\
\text { Initial }\end{array}$ & $\begin{array}{l}96 \pm 11 \\
99 \pm 7\end{array}$ & $\begin{array}{l}98 \pm 14 \\
109 \pm 11 * \#\end{array}$ & $\begin{array}{l}93 \pm 6 \\
108 \pm 7 *\end{array}$ & $\begin{array}{l}95 \pm 8 \\
106 \pm 8 *\end{array}$ \\
\hline HAR & $\begin{array}{l}\text { Final } \\
\text { Initial }\end{array}$ & $\begin{array}{l}100 \pm 6 \\
0.97 \pm 0.06\end{array}$ & $\begin{array}{l}105 \pm 10 \\
1.03 \pm 0.06^{*} \#\end{array}$ & $\begin{array}{l}104 \pm 6 \\
0.99 \pm 0.05^{*}\end{array}$ & $\begin{array}{l}103 \pm 7 \\
1.02 \pm 0.03 *\end{array}$ \\
\hline SSF mm & $\begin{array}{l}\text { Final } \\
\text { Initial }\end{array}$ & $\begin{array}{l}0.96 \pm 0.07 \\
20 \pm 7 *\end{array}$ & $\begin{array}{l}0.92 \pm 0.05 \\
40 \pm 14 * \#\end{array}$ & $\begin{array}{l}0.90 \pm 0.04 \\
41 \pm 13 * \#\end{array}$ & $\begin{array}{l}0.92 \pm 0.04 \\
38 \pm 11^{*} \#\end{array}$ \\
\hline & Final & $24 \pm 9$ & $19 \pm 5$ & $18 \pm 3$ & $20 \pm 5$ \\
\hline
\end{tabular}

$\mathrm{GCo}=$ Control with no nutritional counseling (nutritional counseling)

$\mathrm{GLi}_{50}=$ With nutritional counseling, $60 \mathrm{~g}$ linseed, $50 \%$ of the energy supply as carbohydrates.

$\mathrm{GRi}_{50}=$ With nutritional counseling, $60 \mathrm{~g}$ rice, $50 \%$ of the energy supply as carbohydrates.

$\mathrm{GLi}_{32}=$ With nutritional counseling, $60 \mathrm{~g}$ linseed, $32 \%$ of the energy supply as carbohydrates

Initial collection performed on day zero of the study (baseline time).

Final collection performed at 42 days of the study (final time).

* Statistically significant difference between initial and final times, paired data.

\# Statistically significant difference in relation to the different groups, independent unpaired data.

$\mathrm{n}=$ number of volunteers. $\mathrm{BMI}=$ body mass index. $\mathrm{AC}=$ abdominal circumference. $\mathrm{HC}=$ hip circumference. $\mathrm{HAR}=\mathrm{AC} / \mathrm{HC}$ ratio. $\mathrm{SSF}=$ subscapular fold.

Table 2. Biochemical characteristics related to the lipid and cardiovascular metabolism of the participants in the present study; plasma data.

\begin{tabular}{|c|c|c|c|c|c|}
\hline \multirow[b]{2}{*}{ Biochemistry } & \multicolumn{5}{|c|}{ Experimental groups } \\
\hline & Time & GCo $(n=11)$ & $\mathrm{GLi}_{50}(\mathrm{n}=14)$ & $\operatorname{GRi}_{50}(n=13)$ & $\mathrm{GLi}_{32}(\mathrm{n}=14)$ \\
\hline \multirow[t]{2}{*}{ Glucose $\mathrm{mg} / \mathrm{dL}$} & Initial & $92 \pm 12$ & $93 \pm 11$ & $98 \pm 16$ & $90 \pm 15$ \\
\hline & Final & $88 \pm 13$ & $92 \pm 9$ & $91 \pm 12$ & $88 \pm 10$ \\
\hline \multirow[t]{2}{*}{ Total cholesterol mg/dL } & Initial & $225 \pm 41$ & $191 \pm 34$ & $205 \pm 36^{*}$ & $223 \pm 50^{*}$ \\
\hline & Final & $219 \pm 47$ & $180 \pm 39$ & $180 \pm 31$ & $186 \pm 41$ \\
\hline \multirow[t]{2}{*}{ LDL-c mg/dL } & Initial & $163 \pm 53$ & $120 \pm 29$ & $135 \pm 50^{*}$ & $151 \pm 59 *$ \\
\hline & $\begin{array}{l}\text { Final } \\
\text { Initial }\end{array}$ & $\begin{array}{l}155 \pm 60 \\
40 \pm 10 *\end{array}$ & $\begin{array}{c}107 \pm 35 \\
41 \pm 6\end{array}$ & $\begin{array}{c}110 \pm 26 \\
44 \pm 9\end{array}$ & $\begin{array}{c}116 \pm 35 \\
42 \pm 5^{*}\end{array}$ \\
\hline HDL-c mg/dL & $\begin{array}{l}\text { Final } \\
\text { Initial }\end{array}$ & $\begin{array}{c}39 \pm 8 \\
276 \pm 334\end{array}$ & $\begin{array}{c}40 \pm 4 \\
146 \pm 67\end{array}$ & $\begin{array}{c}42 \pm 7 \\
241 \pm 264\end{array}$ & $\begin{array}{c}42 \pm 5 \\
215 \pm 110\end{array}$ \\
\hline Triglycerides mg/dL & Final & $264 \pm 178$ & $146 \pm 52$ & $144 \pm 56$ & $153 \pm 83$ \\
\hline \multirow[t]{2}{*}{ Uric acid mg/dL } & Initial & $6 \pm 1$ & $6 \pm 1$ & $7 \pm 1^{*}$ & $7 \pm 2 *$ \\
\hline & Final & $6 \pm 2$ & $6 \pm 2$ & $6 \pm 1$ & $6 \pm 3$ \\
\hline \multirow[t]{2}{*}{ Insulin $\mu \mathrm{IU} / \mathrm{mL}$} & Initial & $8 \pm 8$ & $13 \pm 8$ & $18 \pm 14^{*} \#$ & $12 \pm 8$ \\
\hline & Final & $13 \pm 21$ & $11 \pm 7$ & $7 \pm 5$ & $9 \pm 5$ \\
\hline \multirow[t]{2}{*}{ HOMA B } & Initial & $27 \pm 25$ & $47 \pm 35$ & $60 \pm 40 * \#$ & $49 \pm 55$ \\
\hline & Final & $43 \pm 63$ & $39 \pm 27$ & $25 \pm 16$ & $31 \pm 18$ \\
\hline \multirow[t]{2}{*}{ HOMA-IR } & Initial & $2 \pm 2$ & $3 \pm 2$ & $5 \pm 5 * \#$ & $3 \pm 1$ \\
\hline & Final & $3 \pm 6$ & $3 \pm 2$ & $2 \pm 1$ & $2 \pm 1$ \\
\hline
\end{tabular}

$\mathrm{GCo}=$ Control with no nutritional counseling (nutritional counseling)

$\mathrm{GLi}_{50}=$ With nutritional counseling, $60 \mathrm{~g}$ linseed, $50 \%$ of the energy supply as carbohydrates.

$\mathrm{GRi}_{50}=$ With nutritional counseling, $60 \mathrm{~g}$ rice, $50 \%$ of the energy supply as carbohydrates.

$\mathrm{GLi}_{32}=$ With nutritional counseling, $60 \mathrm{~g}$ linseed, $32 \%$ of the energy supply as carbohydrates

Initial collection performed on day zero of the study (baseline time).

Final collection performed at 42 days of the study (final time).

* Statistically significant difference between initial and final times, paired data.

\# Statistically significant difference in relation to the different groups, independent unpaired data.

$\mathrm{n}=$ number of volunteers. LDL-c $=$ low density lipoprotein. HDL-c= high-density lipoprotein. HOMA-B=homeostasis model assessment of pancreatic beta-cell. HOMA-IR= homeostasis model assessment-insulin resistance. 
Table 3. Nutritional intakes by the different experimental groups and the control group at the beginning and at the end of the study.

\begin{tabular}{|c|c|c|c|c|c|}
\hline \multirow[b]{2}{*}{ Nutritional intake } & \multicolumn{3}{|c|}{ Groups } & \multirow[b]{2}{*}{$\operatorname{GRi}_{50}(\mathrm{n}=13)$} & \multirow[b]{2}{*}{$\mathrm{GLi}_{32}(\mathrm{n}=14)$} \\
\hline & Time & $\operatorname{GCo}(n=11)$ & $\mathrm{GLi}_{50}(\mathrm{n}=14)$ & & \\
\hline \multirow[t]{2}{*}{ Energy kcal/d } & Initial & $3454 \pm 367$ & $4188 \pm 931^{*}$ & $3869 \pm 1012 *$ & $3665 \pm 713^{*}$ \\
\hline & Final & $3722 \pm 497$ & $1830 \pm 400$ & $1765 \pm 193$ & $1578 \pm 213$ \\
\hline \multirow[t]{2}{*}{ Carbohydrates g/d } & Initial & $417 \pm 105^{*}$ & $550 \pm 121 * \#$ & $451 \pm 118 *$ & $478 \pm 73 *$ \\
\hline & Final & $476 \pm 95$ & $233 \pm 52$ & $201 \pm 32$ & $159 \pm 28$ \\
\hline \multirow[t]{2}{*}{ Proteins $\mathrm{g} / \mathrm{d}$} & Initial & $183 \pm 49$ & $183 \pm 48 *$ & $187 \pm 53 *$ & $152 \pm 55^{*}$ \\
\hline & Final & $194 \pm 41$ & $94 \pm 22$ & $122 \pm 22$ & $118 \pm 23$ \\
\hline \multirow[t]{2}{*}{ Total fats $\mathrm{g} / \mathrm{d}$} & Initial & $118 \pm 31$ & $150 \pm 52 *$ & $135 \pm 62 *$ & $127 \pm 37 *$ \\
\hline & Final & $117 \pm 22$ & $50 \pm 12$ & $54 \pm 15$ & $55 \pm 11$ \\
\hline \multirow[t]{2}{*}{ Monounsaturated fatty acids $\mathrm{g} / \mathrm{d}$} & Initial & $39 \pm 12$ & $47 \pm 18 *$ & $43 \pm 20^{*}$ & $42 \pm 12 *$ \\
\hline & Final & $39 \pm 9$ & $26 \pm 7$ & $26 \pm 9$ & $19 \pm 6$ \\
\hline \multirow[t]{2}{*}{ Polyunsaturated fatty acids $\mathrm{g} / \mathrm{d}$} & Initial & $27 \pm 7$ & $27 \pm 12$ & $25 \pm 13^{*}$ & $24 \pm 9$ \\
\hline & Final & $28 \pm 6$ & $24 \pm 4$ & $12 \pm 6$ & $24 \pm 5$ \\
\hline \multirow[t]{2}{*}{ Saturated fatty acids $\mathrm{g} / \mathrm{d}$} & Initial & $41 \pm 14$ & $58 \pm 26^{*}$ & $51 \pm 27 *$ & $51 \pm 16^{*}$ \\
\hline & Final & $41 \pm 9$ & $15 \pm 4$ & $13 \pm 3$ & $12 \pm 3$ \\
\hline \multirow[t]{2}{*}{ Cholesterol mg/d } & Initial & $620 \pm 249$ & $607 \pm 203 *$ & $569 \pm 220 *$ & $583 \pm 313 *$ \\
\hline & Final & $597 \pm 177$ & $277 \pm 69$ & $267 \pm 67$ & $248 \pm 59$ \\
\hline \multirow[t]{2}{*}{ Fibers $\mathrm{g} / \mathrm{d}$} & Initial & $45 \pm 13$ & $41 \pm 16$ & $41 \pm 15^{*}$ & $42 \pm 14$ \\
\hline & Final & $46 \pm 10$ & $44 \pm 5$ & $26 \pm 6$ & $41 \pm 5$ \\
\hline \multicolumn{6}{|c|}{ GCo $=$ Control with no dietary counseling (nutritional counseling) } \\
\hline \multicolumn{6}{|c|}{$\mathrm{GLi}_{50}=$ With nutritional counseling, $60 \mathrm{~g}$ linseed, $50 \%$ of the energy supply as carbohydrates. } \\
\hline \multicolumn{6}{|c|}{$\mathrm{GRi}_{50}=$ With nutritional counseling, $60 \mathrm{~g}$ rice, $50 \%$ of the energy supply as carbohydrates. } \\
\hline \multicolumn{6}{|c|}{$\mathrm{GLi}_{32}=$ With nutritional counseling, $60 \mathrm{~g}$ linseed, $32 \%$ of the energy supply as carbohydrates } \\
\hline \multicolumn{6}{|c|}{ Initial collection performed on day zero of the study (baseline time). } \\
\hline \multicolumn{6}{|c|}{ Final collection performed at 42 days of the study (final time). } \\
\hline \multicolumn{6}{|c|}{ * Statistically significant difference between initial and final times $(\mathrm{p}<0.05)$. } \\
\hline \multicolumn{6}{|c|}{ \# Statistically significant difference compared to GCo $(\mathrm{p}<0.05)$. } \\
\hline
\end{tabular}

However, the present study showed that, regardless of the experimental group to which a participant belonged, there were no differences in weight evolution. It was observed that, compared to GCo, the three experimental groups lost weight in an equivalent manner. Therefore, there were no differences between the groups receiving ground linseed and rice regarding anthropometric or biochemical data. This observation once again underscores the importance of well-trained nutritional counseling [20], which had greater relevance in terms of weight loss, and of the possible proper modification of dietary habits. Periodic and constant monitoring with emphasis on the exchange of dietary information taking into account the daily eating habits of the participants was a fundamental factor for the maintenance of dietary adhesion throughout the study (42 days), with a consequent improvement of biochemical indicators.

\section{Conclusion}

More important than the linseed supplementation per se or the proportion of $\mathrm{CH}$ ingested, nutritional counseling was the preponderant factor in the experimental groups regarding energy intake adequate to their activity, weight loss and improved biochemical indicators related to cardio-metabolic changes (cholesterol, lipoproteins, glucose and insulin). The group that did not receive nutrition counseling did not show modifications of the quality and quantity of nutrients present in their initial diet. The hypothesis is that nutrition science applied by well-trained professionals who can transmit coherent and appropriate nutritional information without supporting dietary myths is a viable and economically feasible strategy for the prevention and control of diseases related to life style.

\section{Competing Interest}

The authors affirm that they have no competing of interest to declare.

\section{Author's Contributions}

All of the authors were involved in designing the research. RSLC and JSM conceived and carried out experiments. SFCC and CBM helped with the experiments and analyzed the data. VL and ALGF carried out the literature survey and data manipulation.

\section{Acknowledgments}

The authors are grateful to the laboratory people from 
Industry Primo Schincariol SA, Itu, Brazil, and wish to thank Gilberto JoãoPadovan for chemical expertise and technical support. Research supported by grants from FAEPA, Teaching, Research and Assistance Foundation of the University Hospital, Medical School of Ribeirão Preto, Brazil; Brazilian National Research Council - CNPq (Grant \#306824) and Fundação de Amparo à Pesquisa do Estado de São Paulo, FAPESP, (Grant \#2007/51380-7).

\section{REFERENCES}

[1] R. Barazzoni, A. Aleksova, I. Armellini, M.R. Cattin, M. Zanetti, C. Carriere, M. Giacca, F. Dore, G. Guarnieri, G. Sinagra.Adipokines, ghrelin and obesity-associated insulin resistance in nondiabetic patients with acute coronary syndrome.Obesity (Silver Spring), Vol.20, No.12, 2348-2353, 2012.

[2] O'Keefe JH, Gheewala NM, O'Keefe JO. Dietary strategies for improving post-prandial glucose, lipids, inflammation, and cardiovascular health.Journal of the American College of Cardiology.Vol.51, No.3, 249-255, 2008.

[3] B. Ellison, J.L. Lusk, D. Davis. Loooking at the label and beyond: the effects of calorie labels, health consciousness, and demographics on caloric intake in restaurants.International Journal of Behavioral Nutrition and Physical Activity.Vol.10, No.2, 21-30, 2013.

[4] J.M. Spahn, R.S. Reeves, K.S. Keim, I. Laquatra, M. Kel$\operatorname{logg}$, B. Jortberg, N.A. Clark. State of the evidence regarding behavior change theories and strategies in nutrition counseling to facilitate health and food behavior change.Journal of the American Dietetic Association.Vol. 110, No.6, 879-891, 2010

[5] L.A.S. Santos. O fazer educação alimentar e nutricional: algumas contribuições para reflexão [Practicalfoodandnutritioneducation: some points for reflection]. Revista Ciencia e Saude ColetivaVol.17, No.2, 453-462, $2012 . \quad$ URL http://www.scielosp.org/pdf/csc/v17n2/a18v17n2.pdf

[6] G.A. Bortolini, M. Fisberg. Orientação nutricional do paciente com deficiência de ferro [Nutritionalguidelines for patientswithirondeficiency]. Revista Brasileira de Hematologia e Hemoterapia. Vol.32, No.Supl 2, 105-113, 2010. URL http://www.scielo.br/pdf/rbhh/v32s2/aop70010. pdf

[7] R.S.LCassani, F. Nobre, A. Pazin Filho, A. Schmidt. Prevalence of cardiovascular risk factors in a population of Brazilian industry workers. Arquivos Brasileiros de Cardiologia. Vol.92, No.1, 16-22, 2009. URL http://www. scielo.Br/pdf/abc/v92n1/en_04.pdf

[8] J.M. Ordovas. Genotype-phenotype associations: modulation by diet and obesity. Obesity (Silver Spring).Vol.16, No.Suppl 3, S40-S46, 2008.

[9] NHANES. Anthropometry procedures manual. National Health and Nutrition Examination Survey, 2009. URL http://www.cdc.gov/nchs/data/nhanes/nhanes_09_10/BodyM easures_09.pdf
[10] H. Vannucchi, M.R.D.L. Unamuno, J.S. Marchini. Avaliação do estado nutricional [Assessmentofnutritionalstatus]. Medicina (Ribeirão Preto) Vol. 29, No.1, 5-18, 1996. URL http://www.fmrp.usp.br/revista/1996/vol29n1/avaliacao_esta do_nutricional.pdf

[11] American Diabetes Association. Diagnosis and classification of diabetes mellitus.Diabetes CareVol.28, No.Suppl 1, S37-S42, 2005.

[12] Expert panel on detection, evaluation, and treatment of high blood cholesterol in adults. Executive summary of the third report of the National Cholesterol Education Program (NCEP) Expert panel on detection, evaluation, and treatment of high blood cholesterol in adults (Adult treatment panel III).The Journal of the American Medical AssociationVol. 285, No.16, 2486-2497, 2001.

[13] A.C.J. Vasques, L.E.F.P.L. Rosado, R.C.G. Alfenas, B. Geloneze. Análisecrítica do uso dos índices do Homeostasis Model Assessment (HOMA) naavaliação da resistência à insulina e capacidadefuncional das células- $\beta$ pancreáticas [Critical analysis on the use of the homeostasis model assessment (HOMA) indexes in the evaluation of the insulin resistance and the pancreatic beta cells functional capacity]. Arquivos Brasileiros de Endocrinologia e MetabolismoVol.51, No.1, 1516-1521, 2007. URL http://www.scielo.br/ pdf/abem/ v52n1/a06v52n1.pdf

[14] P.R.F. Costa, A.M.O. Assis, M.C.M. Silva, M.L.P. Santana, J.C. Dias, S.M.C. Pinheiro, N.S. Santos. Mudança nos parâmetros antropométricos: a influência de um programa de intervenção nutricional e exercício físico em mulheres adultas [Change in anthropometricparameters: theimpactof a nutritionalinterventionprogramandphysicalexerciseonadultw omen]. Cadernos deSaude Publica Vol.25, No.8, 1763-1773, 2009.URL http://www.scielo.br/pdf/csp/v25n8 /12.pdf

[15] F.M. Sacks, G.A. Bray, V.J. Carey, S.R. Smith, D.H. Ryan, S.D. Anton, K. McManus, C.M. Champagne, L.M. Bishop, N. Laranjo, M.S. Leboff, J.C. Rood, L. de Jonge, F.L. Greenway, C.M. Loria, E. Obarzanek, D.A. Williamson. Comparison of weight-loss diets with different compositions of fat, protein, and carbohydrates. The New England Journal of MedicineVol.360, No.9, 859-873, 2009.

[16] D. Giugliano, A. Ceriello, K. Esposito. The effects of diet on inflammation: emphasis on the metabolic syndrome. Journal of American College of CardiologyVol.48, No.4, 677-685. 2006.

[17] K. Esposito, M. Ciotola, D. Giugliano. Mediterranean diet, endothelial function and vascular inflammatory markers.Public Health Nutrition Vol.9, No.8A, 1073-1076, 2006.

[18] D.J. Jenkins, C.W. Kendall, G. McKeown-Eyssen, R.G. Josse, J. Silverberg, G.L. Booth, E. Vidgen, A.R. Josse, T.H. Nguyen, S. Corrigan, M.S. Banach, S. Ares, S. Mitchell, A. Emam, L.S. Augustin, T.L. Parker, A. Leiter. Effect of a low-glycemic index or a high-cereal fiber diet on type 2 diabetes: a randomized trial. The Journal of the American Medical Association Vol.300, No.23, 2742-2753, 2008.

[19] D.E. Thomas, E.J. Elliott, L.Baur. Low glycaemic index or low glycaemic load diets for overweight and obesity. Cochrane Database of Systematic ReviewsVol.3, No.3, CD005105, 2007.

[20] A.A. Francis, J.F. Deniset, J.A. Austria, R.K. Lavalleé, G.G. Maddaford, T.E. Hedley, E. Dibrov, G.N. Pierce. Effects of 
dietary flaxseed on atherosclerotic plaque regression.American Journal of Physiology.Heart and Circulatory Physiology Vol.304, No.12,H1743-H1751, 2013.

[21] C.M. Bassett, R.S. McCullough, A.L. Edel, A. Patenaude,
R.K. LaVallee, G.N. Pierce. The $\alpha$-linolenic acid content of flaxseed can prevent the atherogenic effects of dietary trans fat.American Journal of Physiology. Heart and Circulatory Physiology Vol.301, No.6, H2220-H2226, 2011. 